\title{
PERANCANGAN APLIKASI PENCATATAN DATA KERUSAKAN PRODUKSI PT. HAENG NAM BERBASIS WEB
}

\author{
Aep Saepudin ${ }^{1}$, Wanti Rahayu², Gita Kencanawaty ${ }^{3}$ \\ Program Studi Informatika, Fakultas Teknik dan Ilmu Komputer, Universitas Indraprasta PGRI \\ Jalan Raya Tengah No 80, Kelurahan Gedong, Pasar Rebo, Jakarta Timur \\ aep.saepudin94@gmail.com, wanti.reiku@gmail.com, gitakencanawaty@ gmail.com
}

\begin{abstract}
Abstrak
Permasalahan pada PT. Haeng Nam dalam pencatatan data saat ini masih dilakukan secara manual, berdampak pada penyajian informasi dan analisa kerusakan harus menunggu sampai 4 hari kerja untuk menyelesaikan nya dan dilakukan oleh 2 orang admin. Berdasarkan permasalahan tersebut, tujuan dari penelitian ini untuk mempersingkat waktu dalam proses pengolahan data dalam penyajian informasi produksi dan kerusakan dengan menggunakan aplikasi yang sudah berbasis web. Setelah aplikasi ini berjalan, akan mempercepat proses pengolahan data dengan waktu pembuatan laporan 2 hari lebih cepat dan hanya 1 operator input data di masing masing bagian dari yang sebelumnya dilakukan oleh 2 orang. Untuk mencapai tujuan tersebut metode yang digunakan adalah metode grounded research, dimana dalam pengumpulan data dilakukan dengan observasi, wawancara, dan dokumentasi sistem. Hasil dari penelitian ini adalah aplikasi yang dapat memudahkan admin dalam melakukan pencatatan data kerusakan produksi, mempercepat proses pembuatan laporan, dan memudahkan pihak manajemen dalam menganalisa kerusakan.
\end{abstract}

Kata Kunci : Perancangan, Pengolahan Data, Berbasis Web

\begin{abstract}
The problem at PT. Haeng Nam in the recording of current data is still done manually, impacting information presentation and damage analysis should wait until 4 working days to complete it and done by 2 admins. Based on the problems the purpose of this research to shorten the time in the process of data processing in the presentation of production information and damage by using applications that are already web-based. Once this application is running it will accelerate the data processing process with 2 days faster report creation time and only 1 data input operator in each part of the previously done by 2 people. To achieve this goal the method used is the grounded research method in which the data collection is done by observation, interviews, and system documentation. The result of this research is an application that can facilitate the admin in recording production damage data, accelerate the process of creating reports, and facilitate management in analyzing the damage.
\end{abstract}

Keywords: Design, Data Processing, Web-Based

\section{PENDAHULUAN}

PT. Haeng Nam Sejahtera Indonesia adalah sebuah perusahaan spesialis dan produsen peralatan keramik piranti makanan, dan Elegan Bone (New Bone China) yang terletak di Gunung Putri Kabupaten Bogor, dengan penekanan pada produk berkualitas premium, pelayanan prima dan pengiriman yang andal. Namun sayangnya, pada perkembangan teknologi yang semakin maju saat ini, PT. Haeng Nam masih memiliki kelemahan dalam sistem pengolahan data laporan produksi yang masih menggunakan sistem secara manual dan belum tersimpan secara terpadu dalam database, sehingga pengolahan data membutuhkan waktu yang cukup lama karena masih dikerjakan secara manual dan dilakukan oleh beberapa admin untuk merekap. Pengolahan data adalah masa atau waktu yang digunakan untuk mendeskripsikan perubahan bentuk data menjadi formasi yang memiliki kegunaan (Bin Ladjamudin, 2013).

Untuk itu, tujuan dari penelitian ini untuk mengembangkan sebuah sistem baru yang terkomputerisasi pada PT. Haeng Nam dalam pengolahan data produksi dan pencatatan data kerusakan agar pencatatan data produksi dan kerusakan bisa dilakukan secara online. Perancangan aplikasi pencatatan data kerusakan dibangun dengan menggunakan 2 bahasa pemrograman PHP dan JavaScript. PHP merupakan singkatan dari PHP (Hypertext Preprocessor). Perancangan adalah sebuah kegiatan 
merancang dan menentukan cara mengolah sistem informasi dari hasil analisa sistem sehingga dapat memenuhi kebutuhan dari pengguna termasuk di antaranya perancangan user interface (Subhan, 2012). PHP (Hypertext Preprocessor) merupakan bahasa berbentuk script yang ditempatkan dalam server dan diproses di server. Hasilnya yang dikirimkan ke klien, tempat pemakai menggunakan browser (Nugroho, 2014). Bahasa JavaScript adalah bahasa script berdasar pada objek yang memperbolehkan pemakai untuk mengendalikan banyak aspek interaksi pemakai pada suatu dokumen HTML(Taryana \& Koeshaeryatin, 2014). Dari sisi back end nya sendiri data dari aplikasi ini akan disimpan pada database dengan tipe MySql. MySQL merupakan database server yang paling sering digunakan dalam pemprograman PHP. MySQL digunakan menyimpan data dalam database dan memanipulasi data-data yang diperlukan (Buana, 2014).

Manfaat dari diterapkannya aplikasi ini adalah data dapat diakses kapan saja dan dari mana saja melalui website dan informasi dapat diterima dengan cepat sehingga dapat memudahkan admin dalam melakukan pencatatan data kerusakan produksi, mempercepat proses pembuatan laporan, dan memudahkan pihak manajemen dalam menganalisa kerusakan.

\section{PENELITIAN RELEVAN}

Berdasarkan hasil penelitian dari jurnal Vol. I No. 2 Agustus 2015 yang disusun oleh Sartini yang berjudul Sistem Pakar Identifikasi Kerusakan HardwareHandphone dengan Menggunakan Metode Forward Chaining, maka secara umum dapat disimpulkan bahwa dengan adanya sistem pakar kerusakan Handphone berbasis web dapat memudahkan user dalam mendapatkan informasi mengenai gejala-gejala kerusakan hardware ponsel dan solusinya (Sartini, 2015).

Begitu pula diterangkan pada jurnal lain Vol. 4 No. 2 Desember 2019 yang disusun oleh Syamsul Bahri yang berjudul Sistem Informasi Perpustakaan Berbasis Web Pada Sman 1 Cibinong bahwa Sistem informasi yang dirancang dapat membantu memudahkan penyimpanan data dari proses bisnis perpustakaan sekolah dan dapat mengurangi terjadinya kesalahan dalam proses bisnis yang dikarenakan Human Error (Bahri, 2019).

\section{METODE PENELITIAN}

Penelitian ini dalam proses pengumpulan data dilakukan dengan metode grounded research dimana data dikumpulkan berdasarkan fakta di lapangan dan analisa perbandingan dengan tujuan menetapkan sebuah konsep serta pembukitan teori yang dilakukan dalam waktu yang bersamaan. Setelah semua data terkumpul kemudian data tersebut akan dilakukan proses pengolahan sampai menjadi sebuah informasi.

Metode pengumpulan data yang dilakukan antara lain:

1. Studi Pustaka

2. Pengamatan Langsung

3. Wawancara

4. Dokumentasi

\section{Langkah-langkah Pengembangan Sistem}

Dalam perancangan aplikasi pada PT. Haeng Nam adalah menggunakan metode waterfall yang meliputi proses-proses sebagai berikut: 


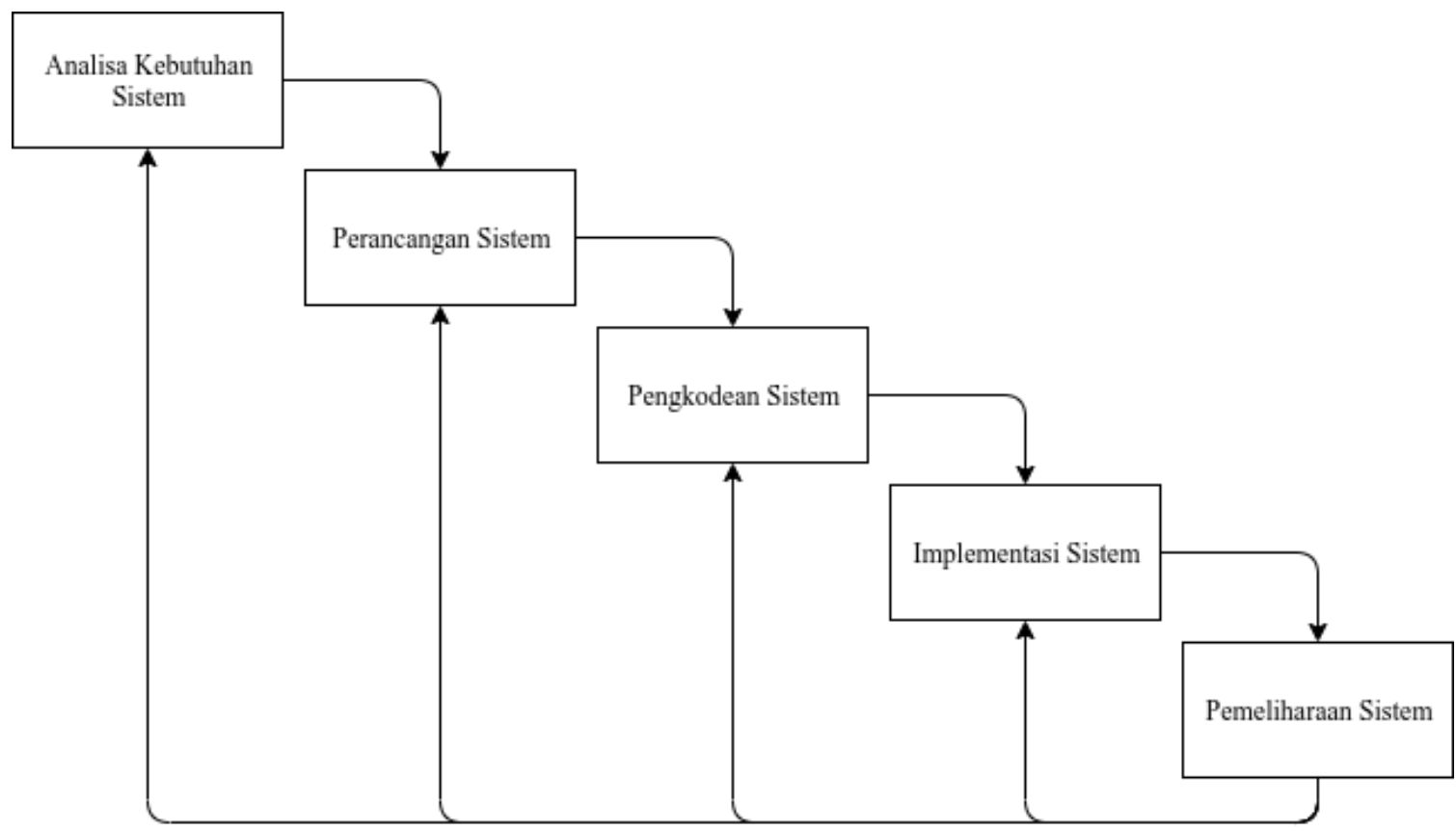

Gambar 1:Tahapan-tahapan Waterfall Model

\section{Analisa Kebutuhan Sistem}

Analisa kebutuhan sistem berguna untuk mendapatkan data-data dan informasi yang nantinya akan digunakan sebagai masukan untuk memperoleh data yang berhubungan dengan sistem yang akan dibuat. Sebelum merancang suatu sistem, hal yang harus dipahami terlebih dahulu adalah memahami kebutuhan pengguna, apa saja yang pengguna inginkan dan yang pengguna perlukan dalam sistem yang akan dibuat.

\section{Perancangan Sistem}

Menyediakan spesifikasi untuk perancangan secara konseptual dan detail berdasarkan perancangan input dan output berupa rancangan semua layer, form-form tertentu, dan laporanlaporan yang dicetak. Database juga dirancang untuk menyimpan dan mengakses data. Struktur dan hubungan antar tabel juga tak kalah penting untuk dipikirkan dari awal untuk memudahkan pengembang data proses pengembangan aplikasi berikutnya.

3. Pengkodean Sistem

Suatu proses menerjemahkan dokumen hasil desain menjadi baris-baris perintah bahasa pemrograman komputer. Semakin baik hasil analisis dan desain yang dilakukan, maka proses pengkodean ini akan lebih mudah dilakukan.

\section{Implementasi Sistem}

Sistem siap untuk dibuat dan diinstalasi dengan sejumlah tugas yang harus dikoordinasikan sebelum melaksanakan untuk implementasi sistem baru.

\section{Pemeliharaan Sistem}

Pemeliharaan sistem berupa perubahan apabila sistem mengalami kesalahan karena harus disesuaikan dengan lingkungan barunya, atau karena pengguna membutuhkan perkembangan fungsional lainnya. Salah satu yang harus disiapkan adalah pemeliharaan database untuk melakukan backup data secara berkala.

\section{HASIL DAN PEMBAHASAN}

\section{Analisis Permasalahan}

Dari hasil penelitian yang dilakukan maka peneliti dapat menganalisa permasalahan yang ada pada proses pendataan PT Haeng Nam, yaitu:

1. Terjadi pengulangan penulisan data kerusakan dan data hasil produksi.

2. Berpotensi kesalahan atau selisih data, karena penulisan data dilakukan secara manual.

3. Boros dalam penggunaan kertas, karena harus membuat rekapan data beberapa salinan untuk didistribusikan ke bagian yang lain. 
4. Penulisan laporan memakan waktu yang cukup lama, karena masih dilakukan secara manual.

\section{Alternatif Penyelesaian Masalah}

Berdasarkan beberapa permasalahan yang terjadi dari analisa tersebut, maka disusunlah beberapa alternatif penyelesaian masalah sebagai berikut:

1. Pencatatan data agar lebih cepat dan akurat harus dilakukan dengan terkomputerisasi yang disimpan dalam database.

2. Setiap kali proses inspeksi dan produksi berlangsung data akan segera dimasukan ke dalam sebuah aplikasi yang akan dibuat.

3. Peneliti mengusulkan aplikasi yang akan digunakan berbasis web, karena cukup mudah digunakan dan tidak perlu install ke setiap komputer cukup menggunakan web browser dan jaringan.

\section{Diagram Alir Data (DAD) Sistem yang Diusulkan}

Dari analisa diatas maka berikutnya aliran data yang diusulkan digambarkan dalam diagram sebagai berikut:

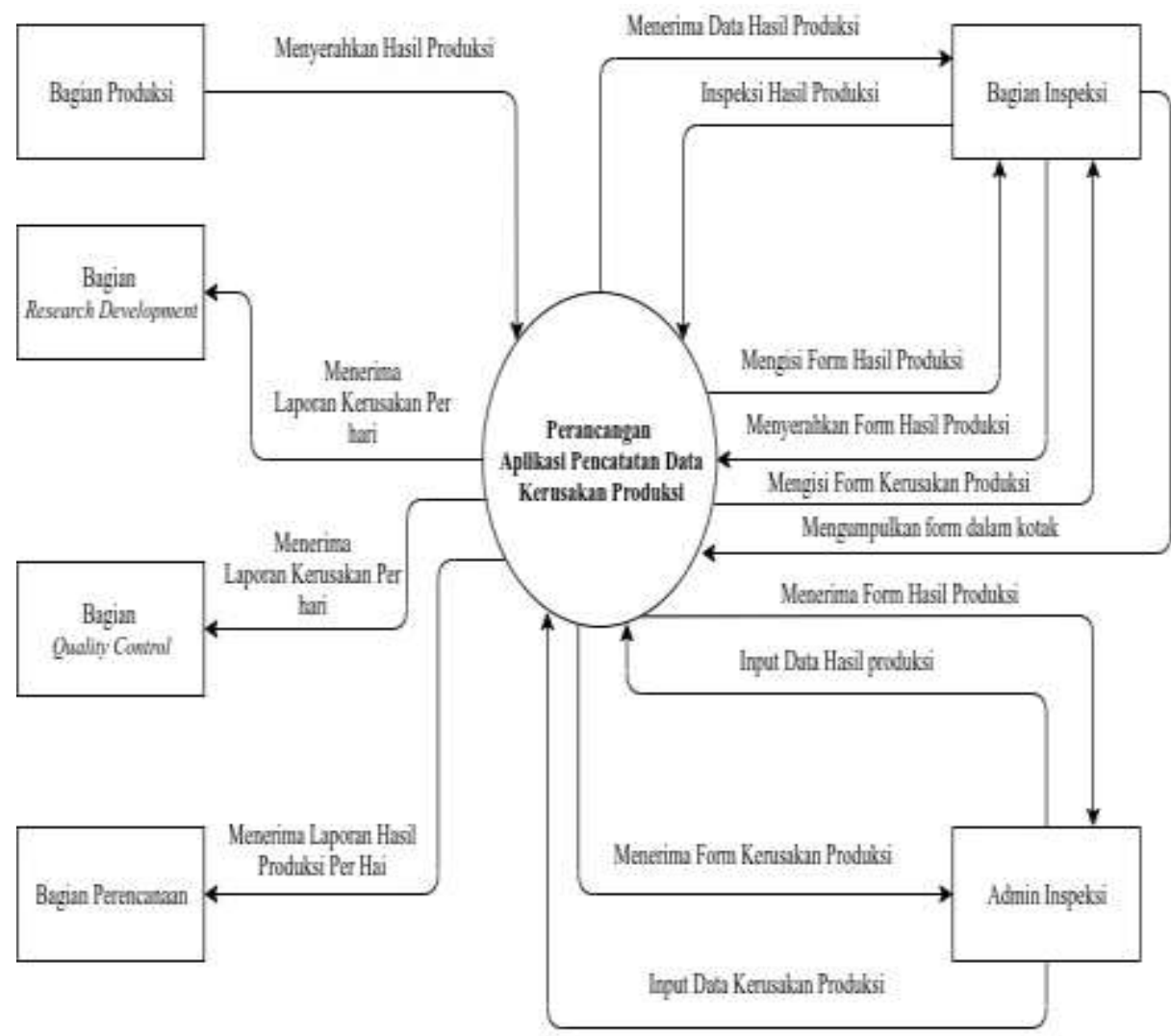

Gambar 2. Diagram Konteks yang Diusulkan

Pada proses usulan ini sudah tidak ada lagi proses rekap data untuk distribusi data laporan ke beberapa departemen yang membutuhkan. Karena aplikasi ini sudah online, bisa diakses dari mana saja. Sehingga untuk departemen yang membutuhkan data laporan cukup masuk saja melalui Aplikasi ini. 


\section{Entity Relationship Diagram (ERD) yang Diusulkan}

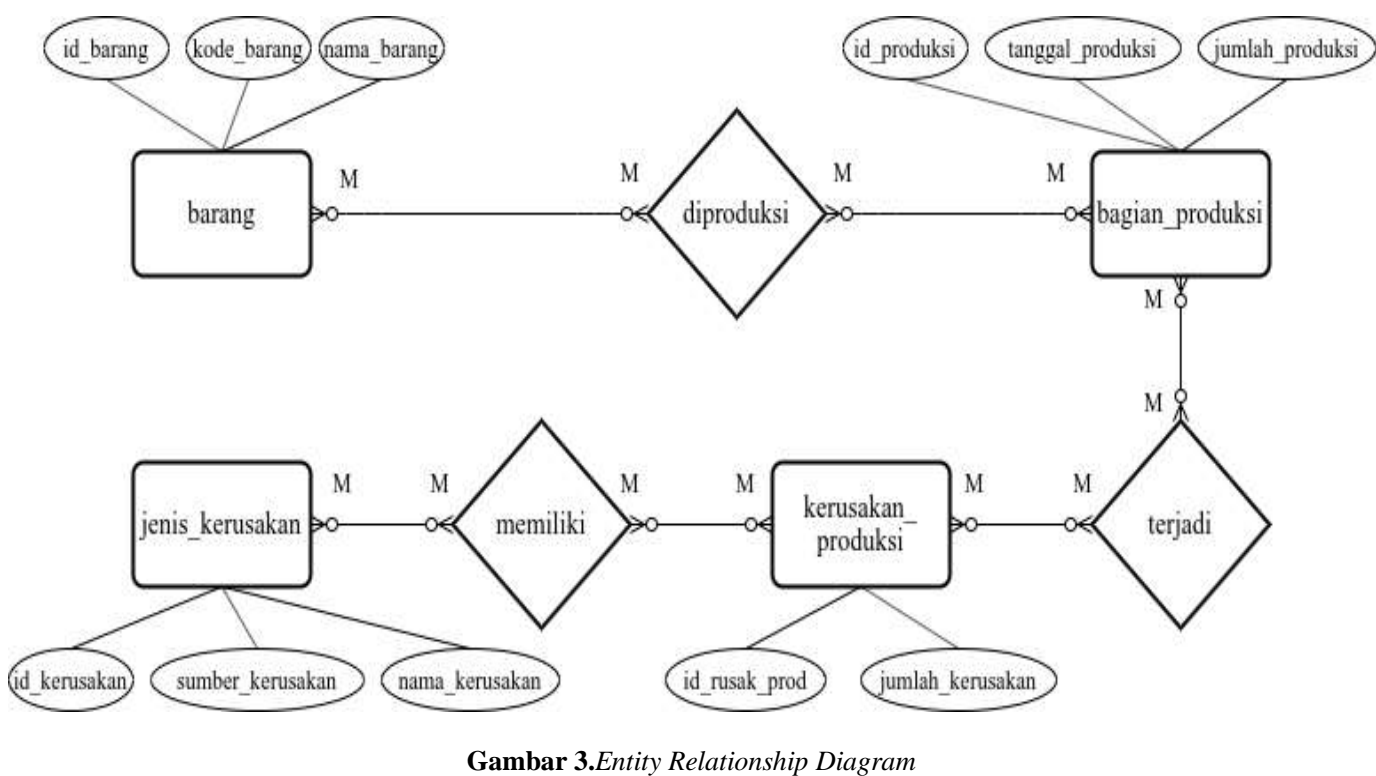

Pada Entity Relationship Diagram ini terdapat 4 entitas, dimana setiap entitas hubungan satu sama lainnya bersifat Many to Many, yang artinya Entitas Barang bias diproduksi oleh beberapa Bagian. Dibeberapa Bagian bisa terjadi sebuah Kerusakan dan setiap Kerusakan bisa memiliki beberapa Kategori/Jenis Kerusakan.

\section{Tampilan Layar Aplikasi Pencatatan Data Kerusakan}

Aplikasi pencatatan data kerusakan ini berbasis web, sehingga dapat digunakan oleh beberapa user melalui browser.

\section{Tampilan Layar Login}

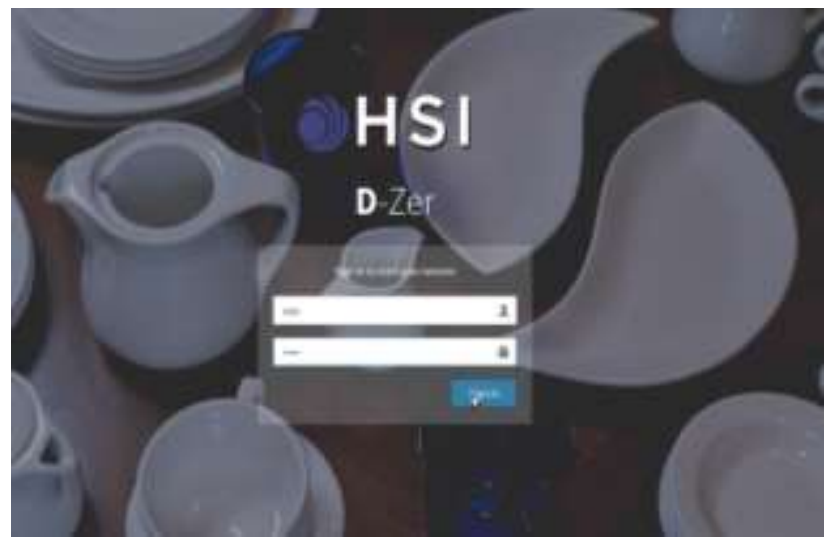

Gambar 4. Tampilan Layar Login

Antarmuka yang disajikan pada aplikasi ini dibuat semudah mungkin agar pengguna tidak mengalami kesulitan dan ditambah beberapa ikon materialize agar tampilan sedikit terlihat lebih menarik dan enak dilihat. 


\section{Tampilan Menu Utama}

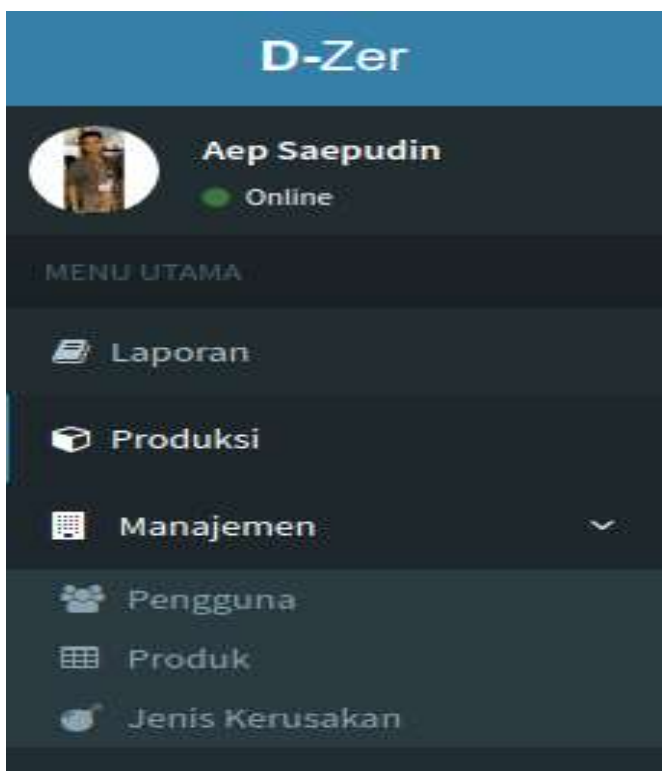

Gambar 5. Tampilan Menu Utama

Secara umum dalam aplikasi ini terdapat 5 menu yang di sediakan. Menu Laporan untuk membuat laporan-laporan untuk dicetak terkait data produksi dan data kerusakan yang sudah diinput sebelumnya. Menu Produksi untuk melakukan input data produksi dan data kerusakan. Dan menu Pengguna, Produk, Jenis Kerusakan untuk memasukan data-data pendukung aplikasi dan data produksi lainnya.

\section{Tampilan Layar Form Input Data Produksi dan Kerusakan}

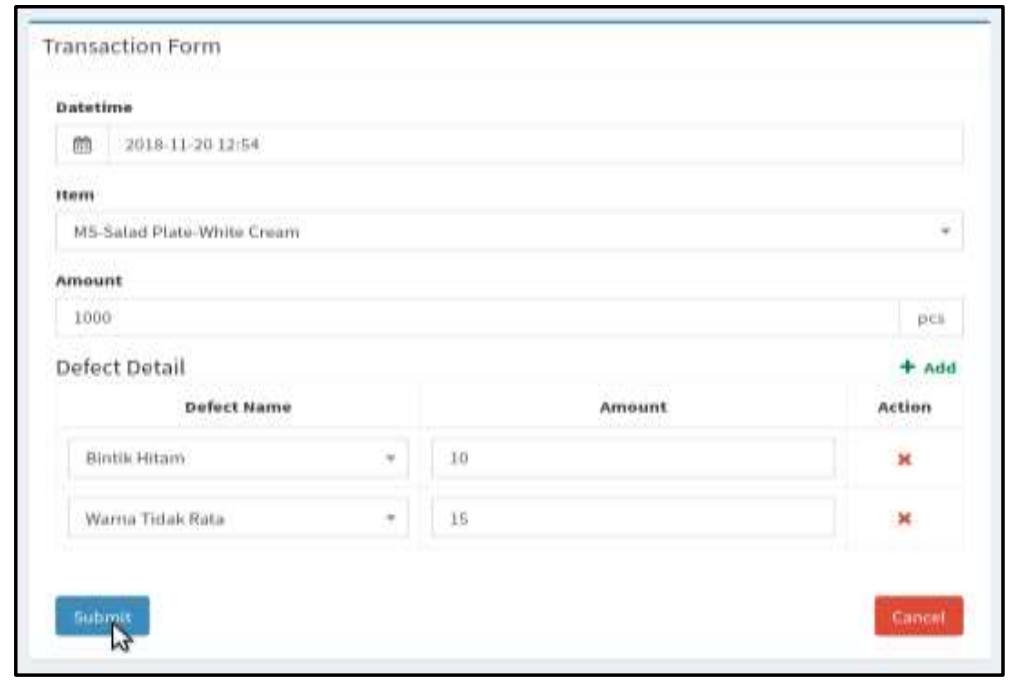

Gambar 6. Tampilan Layar Form Input Data Produksi

Form ini berisi date picker, jenis produk, jumlah produksi serta jenis dan jumlah kerusakan. Form ini akan sangat sering dipakai oleh operator input data. 


\section{Tampilan Laporan Kerusakan Terbesar}

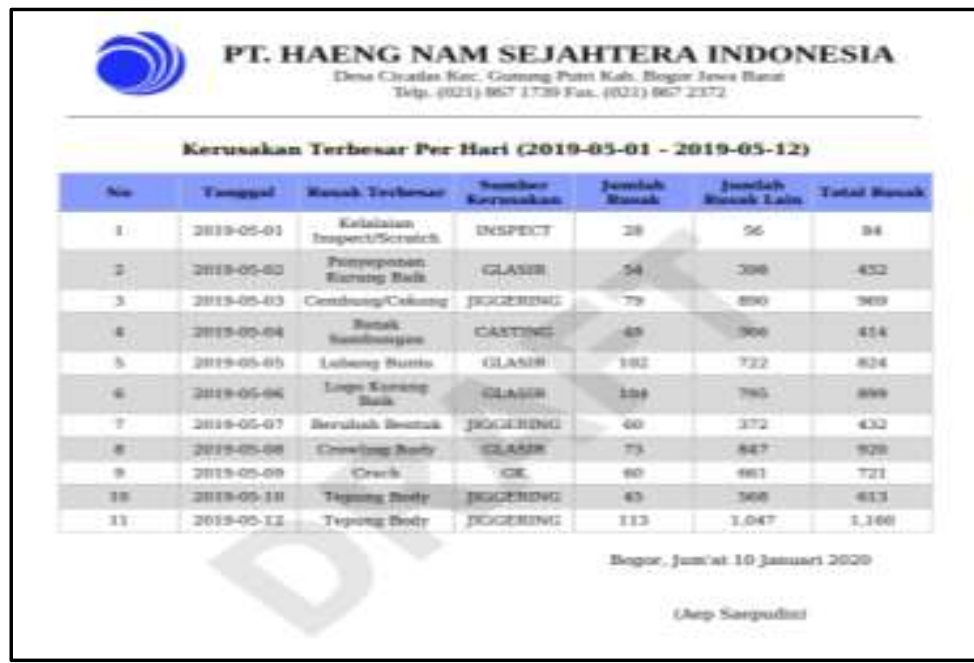

Gambar 7. Tampilan Laporan Kerusakan Terbesar

Laporan ini memberikan informasi jenis kerusakan apa saja yang terjadi setiap hari dengan kuantitas paling besar. Sehingga penanganan kerusakan berikutnya bisa langsung dicegah.

\section{Tampilan Laporan Kerusakan Harian}

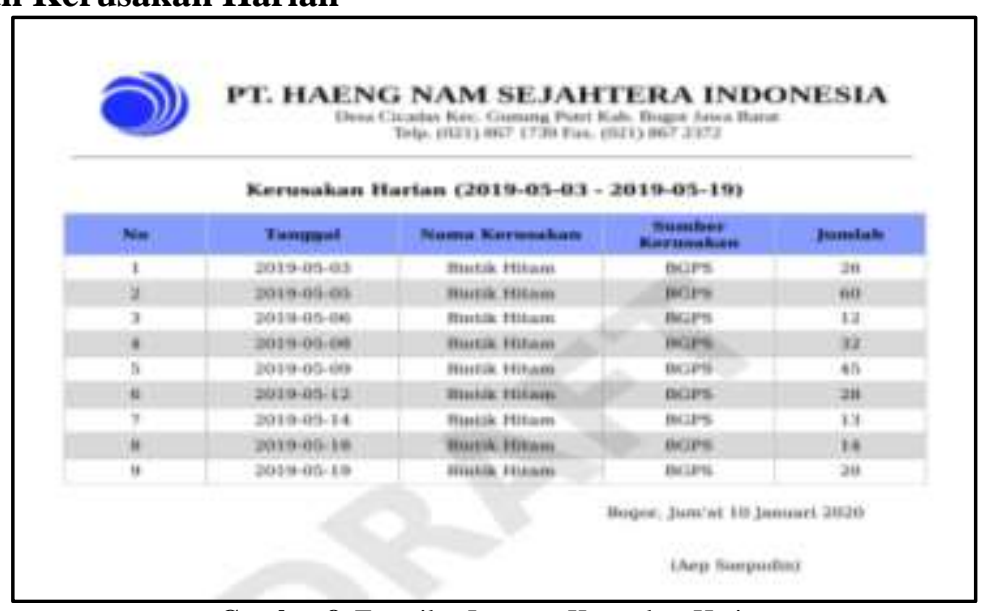

Gambar 8. Tampilan Laporan Kerusakan Harian

Pada laporan ini memberikan informasi 1 jenis kerusakan dengan jumlahnya setiap hari. Jenis kerusakan bisa dipilih sesuai kebutuhan karyawan.

\section{Tampilan Laporan Kualitas Per Item}

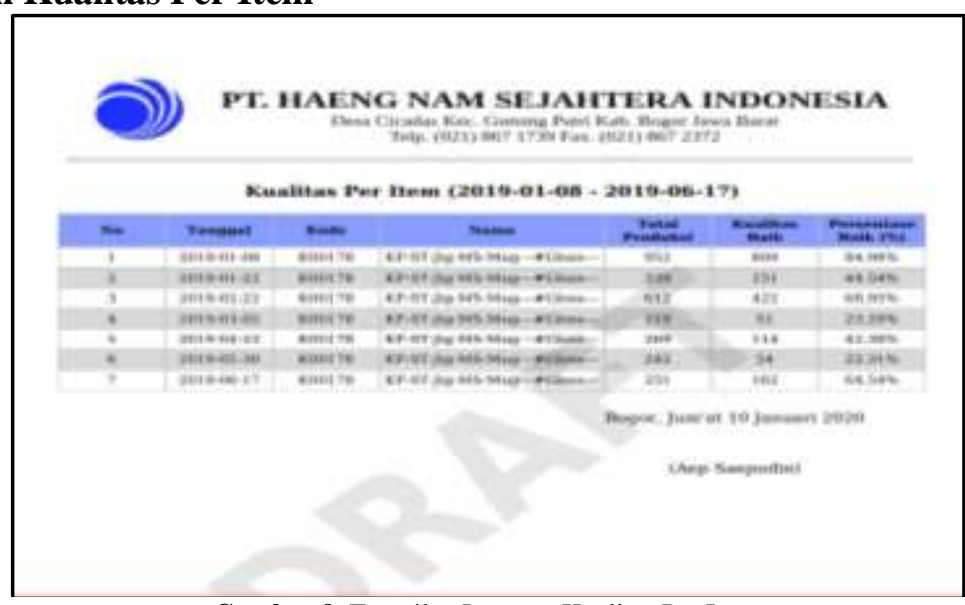

Gambar 9. Tampilan Laporan Kualitas Per Item 
Laporan ini memberikan informasi 1 jenis item atau produk dengan jumlah dan persentase kualitasnya setiap hari. Jenis produk bisa dipilih oleh karyawan sesuai kebutuhan.

Tampilan di atas secara umum adalah semua tampilan yang akan dipakai oleh pengguna dalam mengoprasikan Aplikasi Pencatatan Data Kerusakan.

\section{SIMPULAN}

Dari hasil penelitian ini peneliti menyimpulkan bahwa proses pencatatan data kerusakan dan produksi yang masih dilakukan secara manual menjadi salah satu penyebab dibuatkannya aplikasi ini. Sehingga pembuatan laporan lebih cepat 1 hari daripada sebelumnya. Kemudian proses pencatatan data cukup dilakukan dengan 1 orang dari yang sebelumnya dilakukan oleh 2 orang untuk setiap departemen. Aplikasi ini dirancang menggunakan bahasa pemrograman php (Hypertext Preproccesor) dan berbasis web, sehingga data yang dimasukan bisa dilihat secara online kapan saja dan dimana saja sehingga stakeholder dapat memperoleh data dengan efisien serta tidak memerlukan proses instalasi, karena cukup menggunakan web browser. Antar muka atau desain yang dibuat dirancang sesimpel mungkin sehingga memudahkan pengguna atau stakeholder dalam penggunaan aplikasi ini.

\section{DAFTAR PUSTAKA}

Bahri, S. (2019). Sistem Informasi Perpustakaan Berbasis Web pada SMAN 1 Cibinong. Satuan Tulisan Riset Dan Inovasi Teknologi, 4 No. 2 Des.

Bin Ladjamudin. (2013). Analisis dan Desain Sistem Informasi. Analisis Dan Desain Sistem Informasi. https://doi.org/10.1017/CBO9781107415324.004

Buana, I. komang S. (2014). Jago Pemrograman PHP 2. Politeknik Negeri Sriwijaya.

Nugroho, B. (2014). Dasar Pemrograman Web PHP-MySQL dengan Dreamweaver. Gava Media. https://doi.org/10.1016/0378-1119(87)90155-7

Sartini. (2015). Sistem Pakar Identifikasi Kerusakan Hardware Handphone dengan Menggunakan Metode Forward Chaining. Teknik Komputer AMIK BSI, 1 No.2 Agu.

Subhan, M. (2012). Analisa Perancangan Sistem. In Analisa perancangan sistem.

Taryana, S., \& Koeshaeryatin. (2014). Aplikasi Internet Menggunakan HTML, CSS, dan JavaScript. In Elex Media Komputindo. 